\title{
Surface Catalysis and Oxidation on Stagnation Point Heat Flux Measurements in High Enthalpy Arc Jets
}

Anuscheh Nawaz*, Dave Driver**, Imelda Terrazas Salinas***

Abstract submission for the $44^{\text {th }}$ AIAA Thermophysics Conference

\begin{abstract}
*Sierra Lobo Inc., Thermophysics Facilities Branch, NASA Ames Research Center, MS 229-4, Moffett Field, CA

**Aerothermodynamics Branch, NASA Ames Research Center, MS 230-2, Moffett Field, CA

***Thermophysics Facilities Branch, NASA Ames Research Center, MS 229-4, Moffett Field, CA
\end{abstract}

\section{Symbols and Acronyms}

$\begin{array}{ll}\mathrm{c}_{\mathrm{i}} & \text { Mass fraction of the species, - } \\ \mathrm{h} & \text { Enthalpy, J/kg } \\ \mathrm{p} & \text { Stagnation pressure, } \mathrm{Pa} \\ \mathrm{qw} & \text { Cold wall heat flux, } \mathrm{W} / \mathrm{cm}^{2} \\ \mathrm{R} & \text { Nose radius, } \mathrm{m} \\ \mathrm{T} & \text { Temperature, } \mathrm{K} \\ \mathrm{v} & \text { Velocity, } \mathrm{m} / \mathrm{s} \\ \gamma & \text { Catalytic efficiency, - }\end{array}$

ARC Ames Research Center

$\mathrm{CuO}$ Cupric oxide, black copper oxide

$\mathrm{Cu}_{2} \mathrm{O}$ Cuprous oxide, red copper oxide

TPS Thermal protection systems

ASTM American Society for Testing and Materials

\section{Introduction and Motivation}

Arc jet tests play a critical role in the characterization and certification of thermal protection materials and -systems (TPS). The results from these arc jet tests feed directly into computational models of material response and aerothermodynamics to predict the performance of the TPS in flight. Thus the precise knowledge of the plasma environment to which the test material is subjected, is invaluable. As one of the environmental parameters, the heat flux is commonly measured. The measured heat flux is used to determine the plasma enthalpy through analytical or computational models.

Arc-jets thermally heat gas passing through an arc established between a pair of electrodes. The plasma is then accelerated through a converging diverging nozzle into the test chamber where material models and calorimeters are positioned on 
sting arms, as schematically shown in Figure 1. At NASA Ames Research Center (ARC), slug calorimeters of a geometrically similar shape to the test article are routinely used to determine the heat flux. A slug calorimeter is a thermal capacitance-type calorimeter that uses the temperature rise in a thermally insulated slug to determine the heat transfer rate, see Figure 2. Current best practices for measuring the heat flux with a slug calorimeter are described in ASTM E457-08. ${ }^{i}$ Both the calorimeter body and slug are made of oxygen free high conductivity copper, and are cleaned before each run according to current best practices..$^{\text {ii }}$

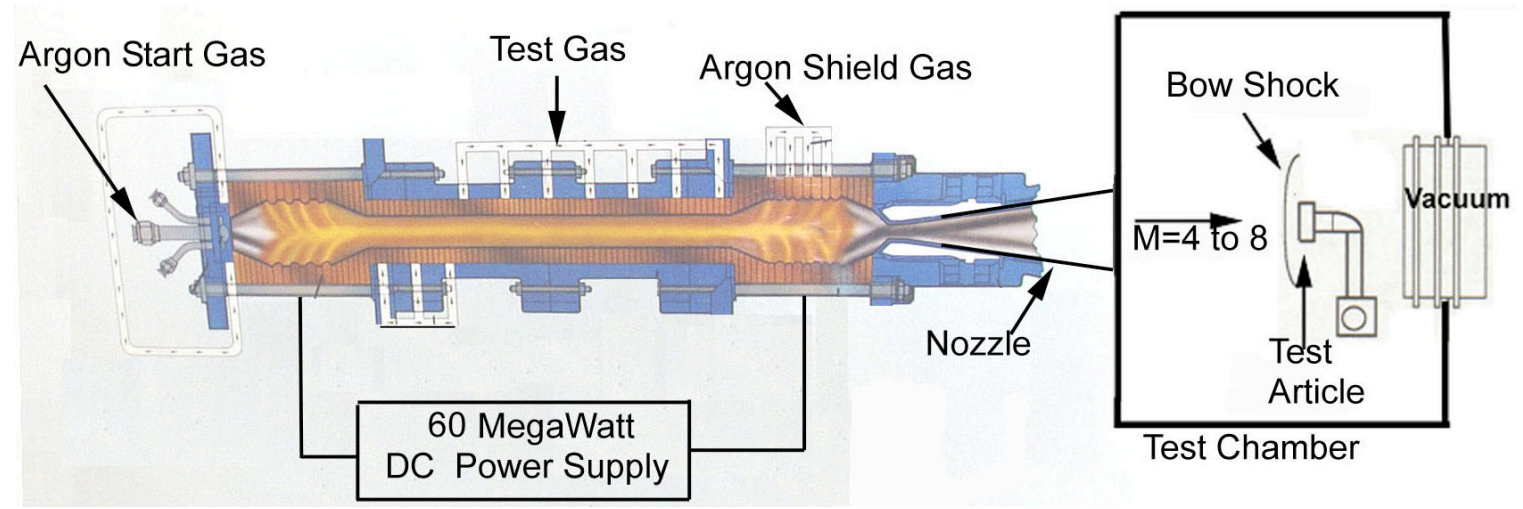

Figure 1. Constricted arc jet working principle. The $\sim 4.5 \mathrm{~m}$ arc (IHF) formed through the constrictor heats the test gas (usually air) which subsequently expands through the nozzle into the test chamber, where heat flux is measured through slug calorimeters.
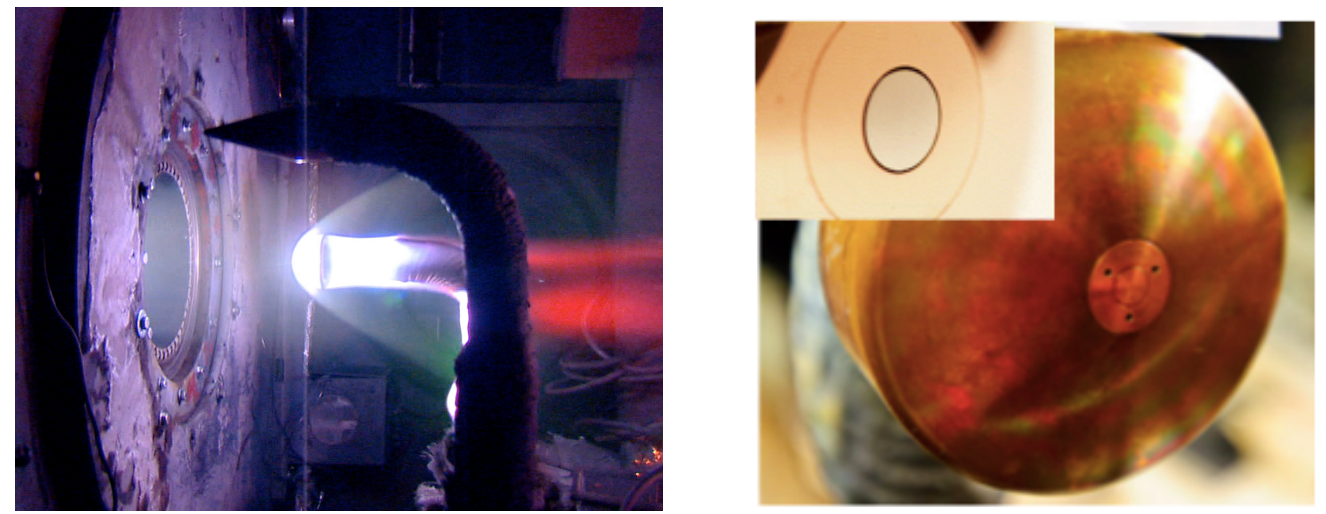

Figure 2. View into the arc jet test chamber during a run (left). Color change of slug calorimeter after the run suggests oxidation of copper.

The enthalpy in plasma can be described as a sum:

$$
h_{\text {plasma }}=\sum_{i} c_{i}\left[\Delta h_{f, i}+h_{i}(T)\right]+\frac{1}{2} v^{2}
$$

where $c_{i}$ mass fraction of the species, $\Delta \mathrm{h}_{\mathrm{f}, \mathrm{i}}$ is the standard enthalpy of formation, and $v$ is the velocity of the plasma. The total enthalpy is thus a sum of the chemical enthalpy (dissociation, ionization), the enthalpy related to the temperature of the 
plasma (rotational, vibrational, translational movement), and the kinetic enthalpy. The catalytic efficiency of the calorimeter surface directly influences the fraction of the chemical enthalpy received by the calorimeter. The lower the catalycity, the smaller the fraction registered. In order to accurately determine the plasma enthalpy from heat flux measurements it is thus required to either have a fully catalytic sensor surface, or to accurately know the catalytic efficiency of the material.

In the recent past, attention has been drawn to the fact that calorimeter surfaces are frequently discolored, pointing to possible surface oxidation, in particular after high enthalpy arc jet runs - see Figure 2 (right).

At certain conditions, an oxidized slug, with a surface composition of $\mathrm{CuO}$ or $\mathrm{Cu}_{2} \mathrm{O}$ could have a significant impact on the heat flux measured. This influence increases with higher enthalpies, lower stagnation pressures, and smaller probe radii.xvi From literature, pure copper is nearly fully catalytic $(\gamma \oplus 0.1)^{\mathrm{iii}}$, whereas copper oxide ( $\mathrm{CuO}$ or $\left.\mathrm{Cu}_{2} \mathrm{O}\right)$ falls into the range of medium catalytic efficiency $(\gamma \approx 0.02)$. iv Thus the heat flux registered, and the enthalpy derived, would be lower for copper oxide than for pure copper when exposed to the same plasma condition. For material tests, the condition in the arc jet is adjusted to meet a required plasma enthalpy. Enthalpies derived from oxidized slugs might be lower than actual, since a portion of the enthalpy is not reflected in the heat flux. Therefore, adjusting arc jet conditions for material tests to the prescribed heat flux would result in an enthalpy test condition higher than required.

A systematic experimental study was conducted in order to determine the degree to which arc jet heat flux measurements are influenced by catalytcity and oxidation effects . It aims at determining the calorimeter surface composition with which current heat flux measurements are taken, evaluating the impact on heat flux, and assessing material options. In particular, the type of calorimeter surface composition change and its timescale is of interest. It is assessed if calorimeter surface composition changes can be avoided in facilities. This would yield a welldefined heat flux measurement.

\section{Methodology}

To achieve the goals described above, the surface of the copper slug calorimeter routinely used at NASA ARC was systematically monitored using X-ray Photon Spectroscopy (XPS) before and after plasma exposure. The plasma exposure was varied in duration and in plasma enthalpy to assess the impact. Further, the surface of the copper slug was changed by depositing a thin layer of materials of interest in a way that did not change the thermal behavior of the slug itself, but allowed to assess the catalytic behavior of the surface. The instruments and methods used are described in the following section. In particular, the slug calorimeter used to measure heat flux, the method of deriving enthalpy for the purpose of comparison within this study, surface analysis, and various material deposition methods are described briefly. 


\section{Slug Calorimeter}

Slug calorimeters are used to determine heat flux for a wide range of applications, including radiative and convective heat flux. Their working principle is based on monitoring the temperature change $\Delta T$ induced in a slug - with density $\rho$ and specific heat $c_{p}$ over the time $t$. The calculation of the heat flux $\dot{q}$ assumes that all incident heat flux is absorbed at the slug surface, and that the heat conduction through the slug can be treated as a one-dimensional problem:

$$
\dot{q}=\rho c_{p} \frac{\Delta T}{\Delta t} .
$$

Further detail on the measurement with slug calorimeters, including some of the error sources, can be found in literature. ${ }^{v}$ At NASA ARC slug calorimeters are used to measure cold wall heat flux. The slugs - cylindrical oxygen free high conductivity copper elements - are mounted in copper bodies matching the geometry of the test article.

A sketch and a model of the design currently used is shown in Figure 3. It is a design developed for an arc jet facility round robin study in 1964vi. These calorimeters are routinely used at ARC in stagnation, and a similar slug design has been tested under shear flow conditions. ${ }^{\text {vii }}$

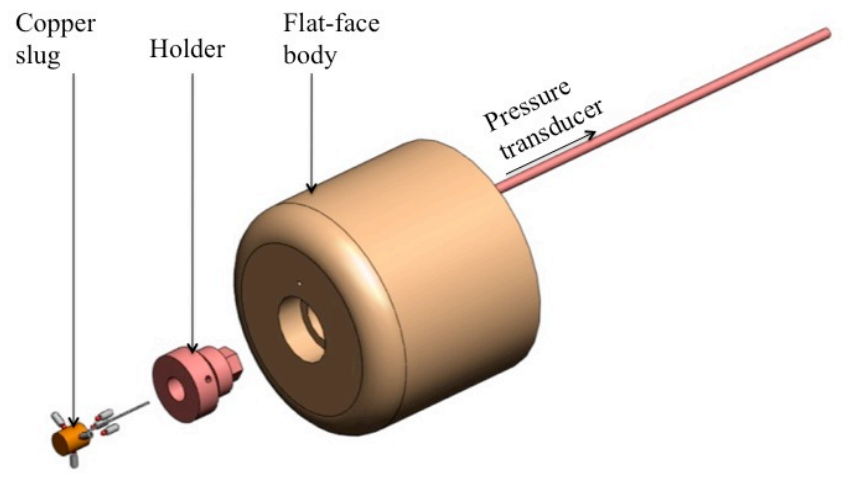

Figure 3. Exploded view of flat-face slug calorimeter, showing assembly.

\section{Enthalpy evaluation}

For thermal protection material characterization it is of great interest to determine the enthalpy in arc jet flow at the centerline where most test samples are positioned. At NASA ARC an empirical estimate of the so-called "bulk enthalpy" (enthalpy

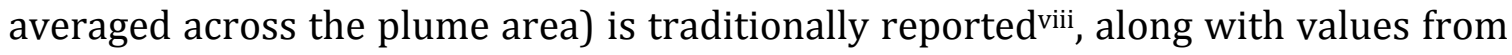
an energy balance using the temperature difference in the arc jet's water cooling circuit. ix Another method is to determine local stagnation point enthalpies based on heat flux measurement, as described in the ASTMviii. The following paragraph discusses methods used within this study. 
Within this study, an enthalpy profile was computed after the ASTMviii,x, based on the radial heat flux and pressure profile measured in the plume using a Nullpoint calorimeter. Only the profile shapes, not their quantities were used to assess how even the enthalpy profile is across the plume. These profiles are shown in Figure 4. For AHF tests, a Nullpoint was swept at all enthalpy conditions tested, for IHF tests this was only the case for the high enthalpy condition (Run 178). A flat distribution of the enthalpy across the plume for both arc jet facilities is noted. Using these profiles, the "peak factor" of centerline deviation from average (bulk) was computed. This factor was 1 for AHF tests (flat distribution) and 1.25 for IHF run 178. Unfortunately, no sweep was obtained for IHF run 179.

The centerline enthalpy reported within this study was calculated by applying this "peak factor" to the bulk enthalpy determined from the empirical formula after Winovich. ${ }^{x i}$ Winovich uses the stagnation pressure, mass flow, and throat area to derive bulk enthalpy of the plume.

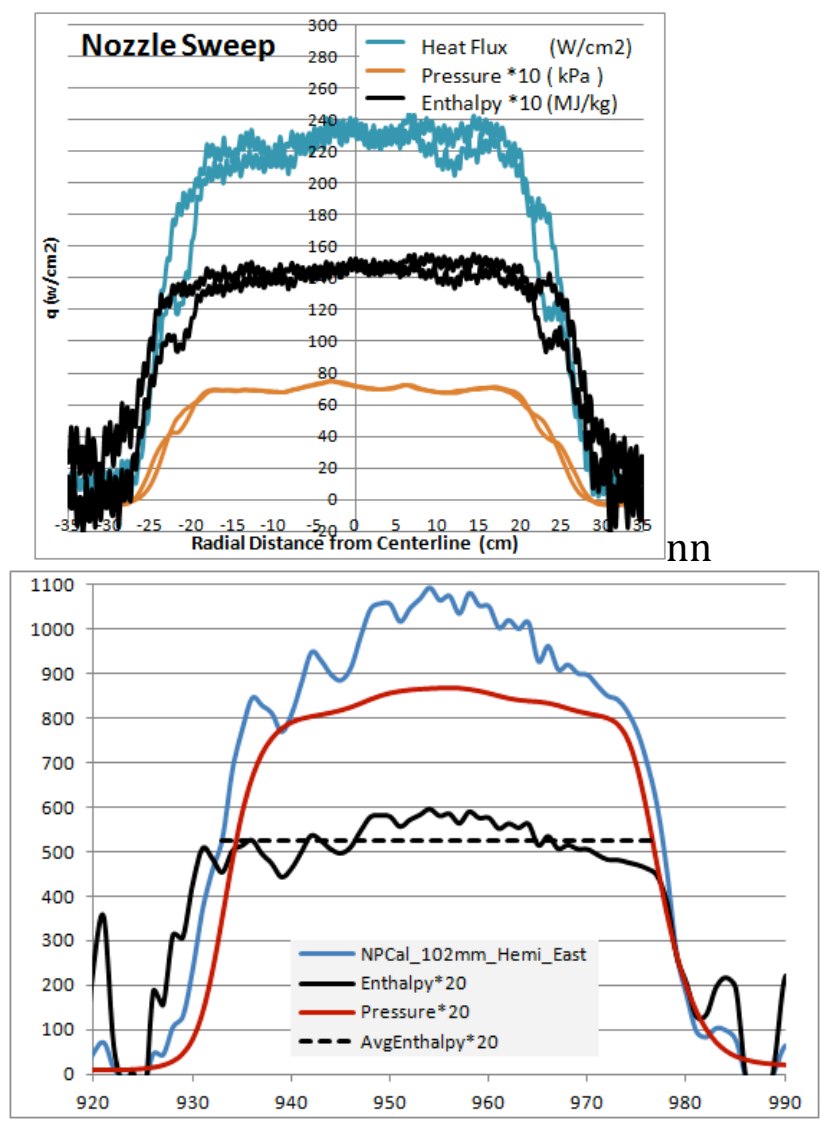

Figure 4. Nullpoint profiles of AHF (left, high enthalpy), and IHF (right, high enthalpy). Enthalpy reported according to ASTM.

In addition, the Data Parallel Line Relaxation code (DPLR) was used in this study.xii DPLR is a CFD tool for the computation of supersonic and hypersonic flows in chemical and thermal nonequilibrium. This first principle code was used to model the impact of surface catalysis on the heat flux measured. 
$\underline{\text { XPS analysis }}$

X-ray Photon Spectroscopy (XPS) is used to analyze the surface composition of the slugs before and after plasma exposure. Monochromatic x-rays are irradiated onto the sample surface, resulting in the emission of photoelectrons whose energies are characteristic of the elements within the sampling volume. The measurement depth is $50-100 \AA$. This technique can be coupled with ion sputtering, to determine an upper boundary for the depth of composition change. This analysis service was provided by Evans Analytical Group (EAG).

\section{Calorimeter Surface Materials}

The surface material on the copper slug was changed to assess the impact of catalysis on heat flux experimentally, and to evaluate changes on the surface of these materials. In order to avoid significant change in thermal conductivity during the slug calorimeter measurement, a very thin layer on the copper slug was desired.

\section{Vapor Deposition: $\mathrm{SiO}_{2}$ coating of copper slugs}

To achieve a low catalytic surface material, while retaining the high conductivity of copper, the copper slug was sputtered with $\mathrm{SiO}_{2}$. In this technique, the solid $\mathrm{SiO}_{2}$ source is bombarded with Argon plasma, which cause it to release and deposit molecular $\mathrm{SiO}_{2}$ onto the strategically placed target material. The deposition layer is $\sim 10 \mathrm{~nm}$ thick. When analyzed with XPS, the $\mathrm{SiO}_{2}$ layer showed a low level of copper atoms exposed to the surface. Scanning Electron Microscopy (SEM) showed an irregular surface, due to the machining grooves on the copper slug, which could lead to irregular deposition and thus a small amount of copper metal exposure. In future, this can be avoided by polishing the slug prior to $\mathrm{SiO}_{2}$ vapor deposition.

\section{Plating of copper slugs}

The plating thickness reached was on the order of $0.025 \mathrm{~mm}$ and metals chosen for this comparison were nickel, gold and platinum. In order to allow good adhesion under thermal stress, and to prevent chemical diffusion of one metal into the other a thin layer of, nickel and then gold was used to achieve platinum plated copper slugs.

\section{Brazing of Constantan}

Since Constantan is a $45 \%$ to $55 \%$ mixture of nickel and copper, it was brazed onto the copper slug as a finished sheet. The thickness of the sheet was $0.13 \mathrm{~mm}$.

\section{Experiment}

In order to establish a baseline, the surface composition of three slugs not exposed to plasma was evaluated prior to the test series with the aim of understanding the possible change in surface composition of the copper slugs without exposure to plasma. For this, the slug surfaces were cleaned with $\mathrm{Wenol}^{\mathrm{TM}}$, according to current best practices at the NASA Ames arc jet facilitiesii, and then either immediately stored in inert environment (argon), or exposed to room temperature air for $1 \mathrm{~h}$ 
before surface analysis. In addition, one slug was mechanically cleaned with 1200 grit sandpaper and immediately stored in an argon environment.

Tests were performed in two facilities: The Aerodynamic Heating Facility (AHF) and the Interaction Heating Facility (IHF) at NASA Ames Research Center. Both facilities use constrictor-type arc heaters (of the type shown in Figure 1) at input power levels of $20 \mathrm{MW}$ and $60 \mathrm{MW}$, respectively. Test parameters used in this investigation are shown in Table 1 below. Tests were conducted in AHF first, and, based on the results, conditions and surface materials were determined for IHF test runs.

Post-test analysis was performed using XPS, described above. All tests were performed with a $102 \mathrm{~mm}$ diameter hemispherical slug calorimeter in stagnation mode.

During testing, a copper slug was swept through the flow within $0.3 \mathrm{~s}$ to assess how quickly the surface composition changes in one test. A slug was exposed to the normal duration for a stagnation point heat flux measurement of 1-3s in another test. From these tests, stagnation heat flux was obtained, and the post-test surface composition was analyzed.

Table 1. Test parameters for slug calorimeters exposed in arc jets.

\begin{tabular}{lll} 
& IHF & AHF \\
\hline Nozzle Exit Diameter & $33 \mathrm{~cm}$ & $46 \mathrm{~cm}$ \\
\hline Enthalpy & $15.4,26.2 \mathrm{MJ} / \mathrm{kg}$ & $6,15,16 \mathrm{MJ} / \mathrm{kg}$ \\
\hline Stagnation pressure & $13.5 \mathrm{kPa}, 43.5 \mathrm{kPa}$ & $7.9 \mathrm{kPa}, 5.0 \mathrm{kPa}, 4.8 \mathrm{kPa}$ \\
\hline Test Gas & $\mathrm{Air}$ & $\mathrm{Air}$ \\
\hline Slug Surface Materials & $\mathrm{CuO}, \mathrm{Cu}, \mathrm{SiO}_{2}, \mathrm{Pt}$ & $\mathrm{Cu}, \mathrm{Ni}, \mathrm{Pt}$, Constantan, $\mathrm{Au}$
\end{tabular}

Inserting materials other than copper and subsequently analyzing their surface not only allowed to compare heat flux values and catalycity, but assess the purity of the arc jet generated plasma. As described in earlier emission experiments at NASA ARC, and in arc jet experiments at other facilities, copper vapor stemming from the electrodes is present in the plasma. This vapor can potentially deposit on cold surfaces such as calorimeters. The aim was to identify how quickly this deposition happens, and if it influences the heat flux measured with these non-copper materials.

In addition, a copper slug was exposed to cold microwave plasma to explore oxidation behavior. The slug stayed at approximately room temperature during the exposure to oxygen plasma. The microwave plasma is expected to have about $4 \%$ dissociation.

All slugs were stored in an argon filled container after the tests to minimize deposition of organic materials onto the surface, and/or further oxidation prior to surface analysis. 


\section{Results}

\section{Copper Slug Surface Composition}

All three slugs cleaned and stored in an argon environment were oxidized to cuprous oxide, $\mathrm{Cu}_{2} \mathrm{O}$. This was the case regardless of chemical $\left(\mathrm{Wenol}^{\mathrm{TM}}\right.$ ) or mechanical (Sandpaper, 1200 grit) cleaning of the surface. It is estimated that the exposure time to room air was about 15 seconds after cleaning before being stored in inert gas. This leads to the conclusion that all copper slugs used in the arc jet are $\mathrm{Cu}_{2} \mathrm{O}$ before exposure to plasma. This result agrees well with literature, where copper oxidation at room temperature was reported to be a parabolic function of time, occurring within a few seconds after exposure to oxygen. ${ }^{x i i}$

Exposure of copper slugs to air plasma changes the surface composition from cuprous oxide to cupric oxide, $\mathrm{CuO}$. This was observed to be the case for all levels of plasma enthalpy tested. The surface analysis report on all slugs exposed to plasma showed that - neglecting the naturally present organic materials - more than $80 \%$ of the probed volume $(50-100 \AA$ depth, $1400 \mu \mathrm{m} \times 300 \mu \mathrm{m}$ area) consists of $\mathrm{CuO}$, the rest being $\mathrm{Cu}_{2} \mathrm{O}$. It must be noted that surface color does not seem to be a reliable indicator for these low depths of oxidation. While it is safe to associate a discoloration with change in surface composition, the reverse argument cannot be made. Figure 5 shows the slugs after the tests in AHF. The $5 \mathrm{MJ} / \mathrm{kg}$ condition in particular very closely resembles the surface color of the unexposed slug, falsely leading to the conclusion that no oxidation took place. XPS analysis shows all these slug surfaces to consist of $\mathrm{CuO}$. A higher enthalpy condition seems to change the oxide layer thickness, which in turn is responsible for the change in color.

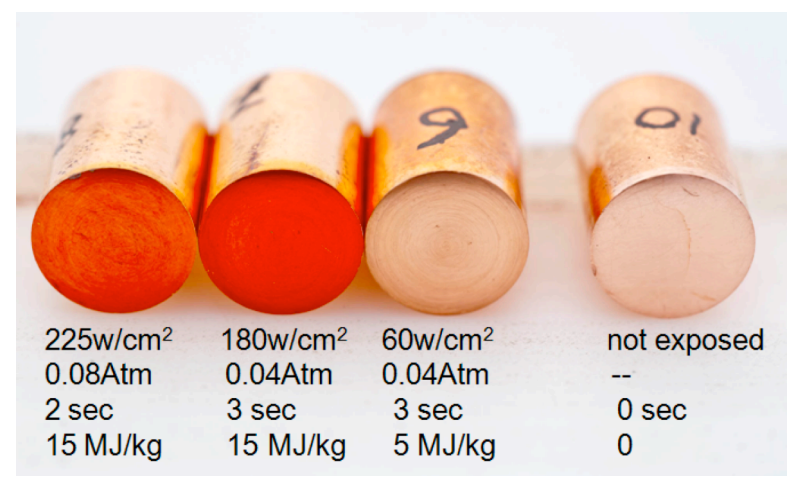

Figure 5. Slug surfaces after AHF tests.

Exposing the cuprous oxide surface $\left(\mathrm{Cu}_{2} \mathrm{O}\right)$ to microwave plasma as described above also yielded a cupric surface $(\mathrm{CuO})$. This leads to the conclusion that the slug does not have to be at elevated temperatures to form cupric oxide - exposure to dissociated oxygen is sufficient.

\section{Surface Composition of Other Materials}


The surface composition of materials other than copper was evaluated. Nickel, platinum, constantan, gold and silicon dioxide were analyzed after exposure to plasma. In addition, silicon dioxide coated slugs were analyzed before plasma exposure for baseline information.

It was found that with the exception of $\mathrm{SiO}_{2}$, all slug surfaces are coated with $\mathrm{CuO}$ after plasma exposure. $\mathrm{SiO}_{2}$ slugs were coated with $\mathrm{Cu}_{2} \mathrm{O}$. Copper oxide coating was observed in both arc jet facilities under all conditions tested. It was also observed for sweeps (0.3s) as well as insertions for 1-3s. Arc jets have long been known to show copper impurities stemming from the electrodes in their plasma. This copper vapor deposits on the surface of the relatively cold slug and forms $\mathrm{CuO}$ by being exposed to air plasma.

At this point it is unclear if the same vapor deposition occurs during material tests performed in the arc jet. This will depend on the material used, as well as the heat flux condition and surface temperature reached. It is planned to address this in a separate study.

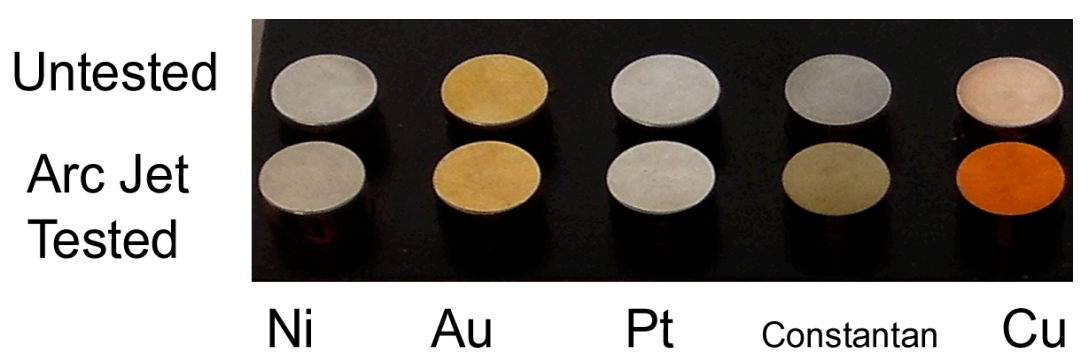

Figure 6. Nickel, Gold, Platinum, Constantan and Copper surfaces pre-and post plasma exposure.

\section{Possible Constant Catalytic Efficiency Surface}

The observations above make $\mathrm{CuO}$ uniquely qualified as calorimeter material, since this is the only material that does not change its surface composition during plasma exposure in an arc heater. For this reason copper slugs were heat-treated in an oven with the goal of forming a robust $\mathrm{CuO}$ layer on their surface. As shown in Figure 7, this was achieved at $800^{\circ} \mathrm{C}$ with 30 minutes exposure time. Although it should be noted that if ideal conduction from the oven to the slug existed, much less time would be sufficient to heat the slug uniformly to $800^{\circ} \mathrm{C}$. A slug similar to the one shown on the far right in Figure 7 was successfully tested in IHF.

The CuO slug surface did not show any signs of flaking after the run, and the XPS analysis surface composition confirmed a pure cupric oxide. However, depending on logistic advantages, there is no inherent benefit of this relatively thick $\mathrm{CuO}$ layer in comparison to a thinner layer on the molecular surface level. The thinner layer could be achieved for example by sweeping the slug through the arc jet stream once before the measurement, or by exposing the slug to low temperature microwave plasma pior to the calorimeter build. As shown in this study, exposing a cold copper surface to dissociated oxygen already results in the formation of $\mathrm{CuO}$ at the surface. 
In order to effectively use $\mathrm{CuO}$ slug calorimeters in the future, their catalytic efficiency must be well known. The catalycity value of $\mathrm{CuO}$ is planned to be assessed at NASA ARC through side arm reactor studies. This will include the dependency of catalycity on surface temperature, as slug temperatures usually rise during the measurement. Literature reports catalycity values of $\gamma_{\mathrm{CuO}}=0.02$ for $\mathrm{CuO}$.iv

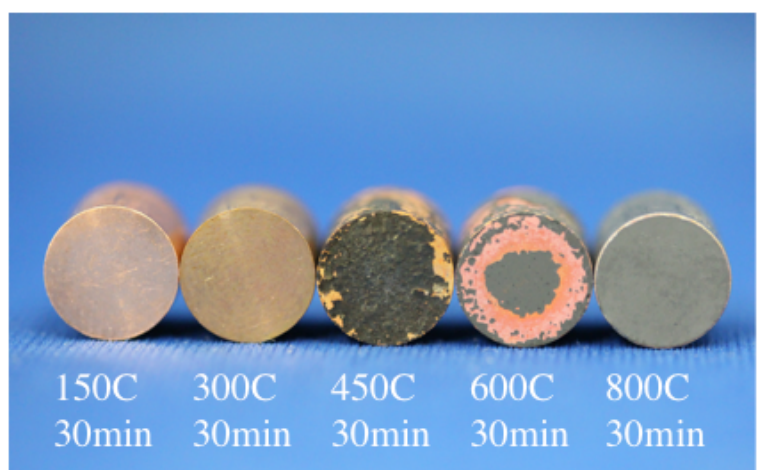

Figure 7. Cupric oxide (CuO) coated slugs, pre-treated in oven.

Heat Flux Comparison

Multiple materials were compared within this study at five test conditions, as shown in Table 2 below. The impact of copper vapor deposit on the surface will be discussed below.

Table 2. Test conditions for multiple materials.

\begin{tabular}{cccc} 
& Stagnation Pressure $[\mathrm{kPa}]$ & Enthalpy $[\mathrm{MJ} / \mathrm{kg}]$ & Surface Material \\
\hline $\mathrm{AHF}$ & 7.9 & 16 & $\mathrm{Ni}, \mathrm{Pt}, \mathrm{Au}, \mathrm{Cu}$, Constantan \\
\hline & 5.0 & 15.5 & $\mathrm{Ni}, \mathrm{Pt}, \mathrm{Au}, \mathrm{Cu}$, Constantan \\
\hline $\mathrm{IHF}$ & 4.8 & 5.7 & $\mathrm{Ni}, \mathrm{Pt}, \mathrm{Au}, \mathrm{Cu}$, Constantan \\
\hline & 43.5 & 26.2 & $\mathrm{Cu}, \mathrm{Pt}$ \\
\hline & 13.5 & 15.4 & $\mathrm{CuO}, \mathrm{SiO}_{2}, \mathrm{Pt}$
\end{tabular}

Heat flux values obtained from the different materials were compared to the standard method of inserting the copper slug only. The deviation $\varepsilon$ of heat flux between the copper slug and the non-copper material in percent is calculated through

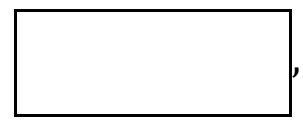

where the subscript i denotes the respective material. Results from the AHF test series are depicted in Figure 8. Deviations range between $-4 \%$ and $+6 \%$ for the two arc jet conditions considered. For the higher enthalpy test, the heat fluxes from the various materials seem to be grouped, with $\mathrm{q}_{\text {constantan }}>\mathrm{q}_{\text {gold }}>\mathrm{q}_{\text {nickel }}>\mathrm{q}_{\text {platinum. The }}$ reason for this is not fully understood, the lower enthalpy test does not reflect the 
same order, and the order does not align with the catalytic values for these materials. Catalytic recombination values reported in literature show nickel, constantan and cupric oxide in the same range $(\gamma=2.5 \mathrm{e}-2$ to $9 \mathrm{e}-2)$, and gold and platinum an order of magnitude lower $(\gamma=5 \mathrm{e}-3)$. ${ }^{\mathrm{iv}, \mathrm{xiv}, \mathrm{xv}}$ This is neither qualitatively not quantitatively represented in the AHF tests results. The parameter nose radius $\mathrm{R}$, stagnation pressure $\mathrm{p}$, and heat flux $\mathrm{q}$ is plotted against plasma centerline enthalpy obtained as described in section "Methodology" above, see Figure 9. The experimental values from the copper slug fall onto the $\gamma=0.02$ line. This agrees with the catalysis value of $\mathrm{CuO}$ found in literature, knowing that the surface formed $\mathrm{CuO}$ when exposed to plasma within a fraction of a second. However, the experimental values for platinum and gold were expected to fall below the $\gamma=0.01$ line, and thus differ from the copper measurement by more than $15 \%$, which was not observed.

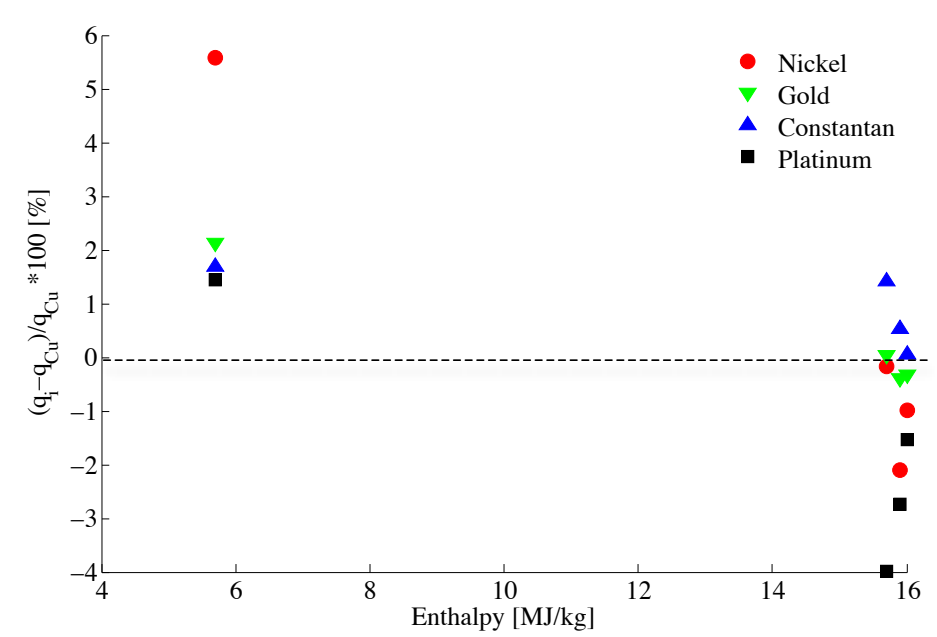

Figure 8. Relative deviation to heat flux measurements with copper for AHF test results.

A possible explanation can be concluded from the surface analyses presented above. All materials tested showed a $\mathrm{CuO}$ coating after the run, which could lead to the very similar heat flux values observed. Deviations in the range of $6 \%$ could thus be caused by changing material properties during the run in combination with measurement uncertainty.

In the IHF test runs, a clear difference in heat flux between silicon dioxide and copper slug surface material was observed, with the $\mathrm{SiO}_{2}$ slug reading $\sim 20 \%$ lower, as seen in Figure 10. This was qualitatively expected, however the DPLR model predicts differences in the order of $50 \%$. This trend is shown in the catalysis lines in Figure 11. A reason for the smaller difference between copper oxide slugs and $\mathrm{SiO}_{2}$ coated slugs is that $\mathrm{SiO}_{2}$ was shown to have accumulated a $\mathrm{Cu}_{2} \mathrm{O}$ layer on its surface, as reported above. Figure 11 depicts the experimental points for copper, $\mathrm{SiO}_{2}$ and platinum. Due to the large error associated with determining the enthalpy, no 
conclusion can be drawn from these experiments at this point. In fact, the results obtained contain contradictions, in particular copper oxide results aligning with catalytic values in the wide range of 0.1 and 0.005 . Determining centerline enthalpies with confidence and modeling of catalytic values, in particular in case of the IHF must be the focus of further investigation.

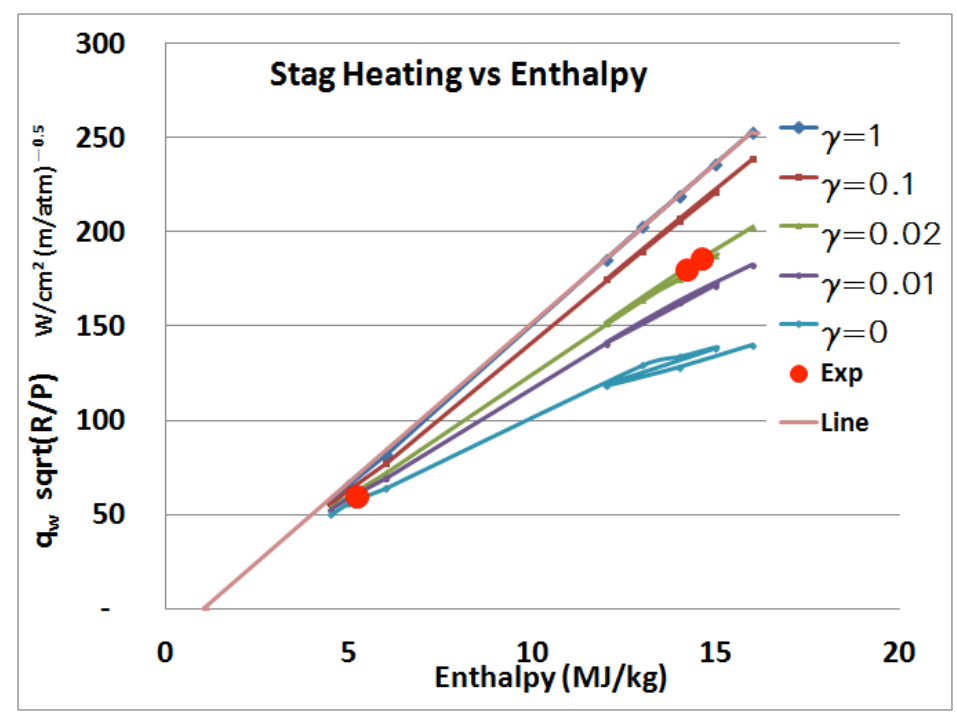

Figure 9. Parameter $\dot{q} \sqrt{\frac{R}{p}}$ versus centerline enthalpy for different catalytic values $\gamma$. Lines obtained with DPLR simulation, experimental values from AHF copper slug.

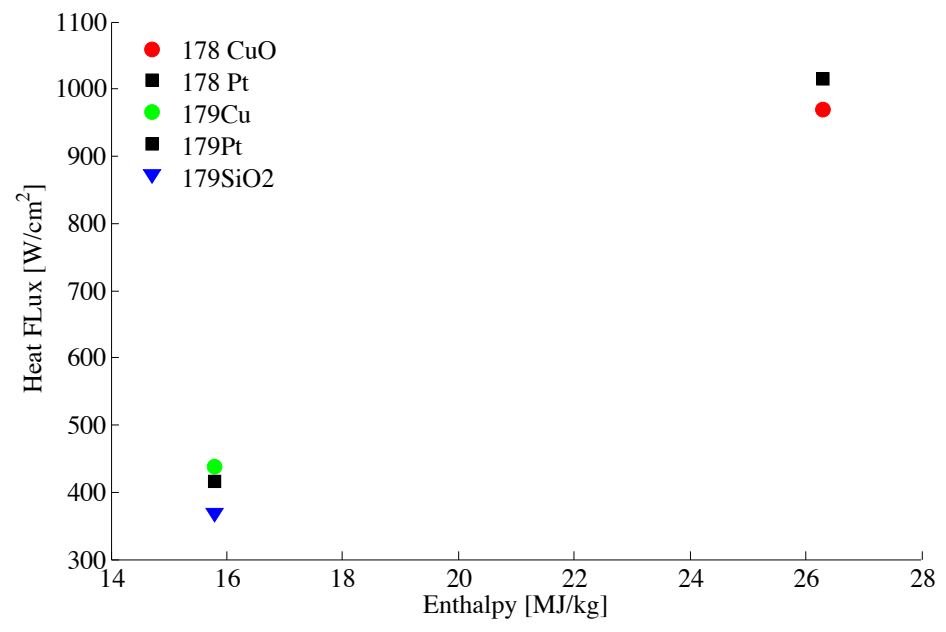

Figure 10. Heat flux versus enthalpy for measurements in IHF. 


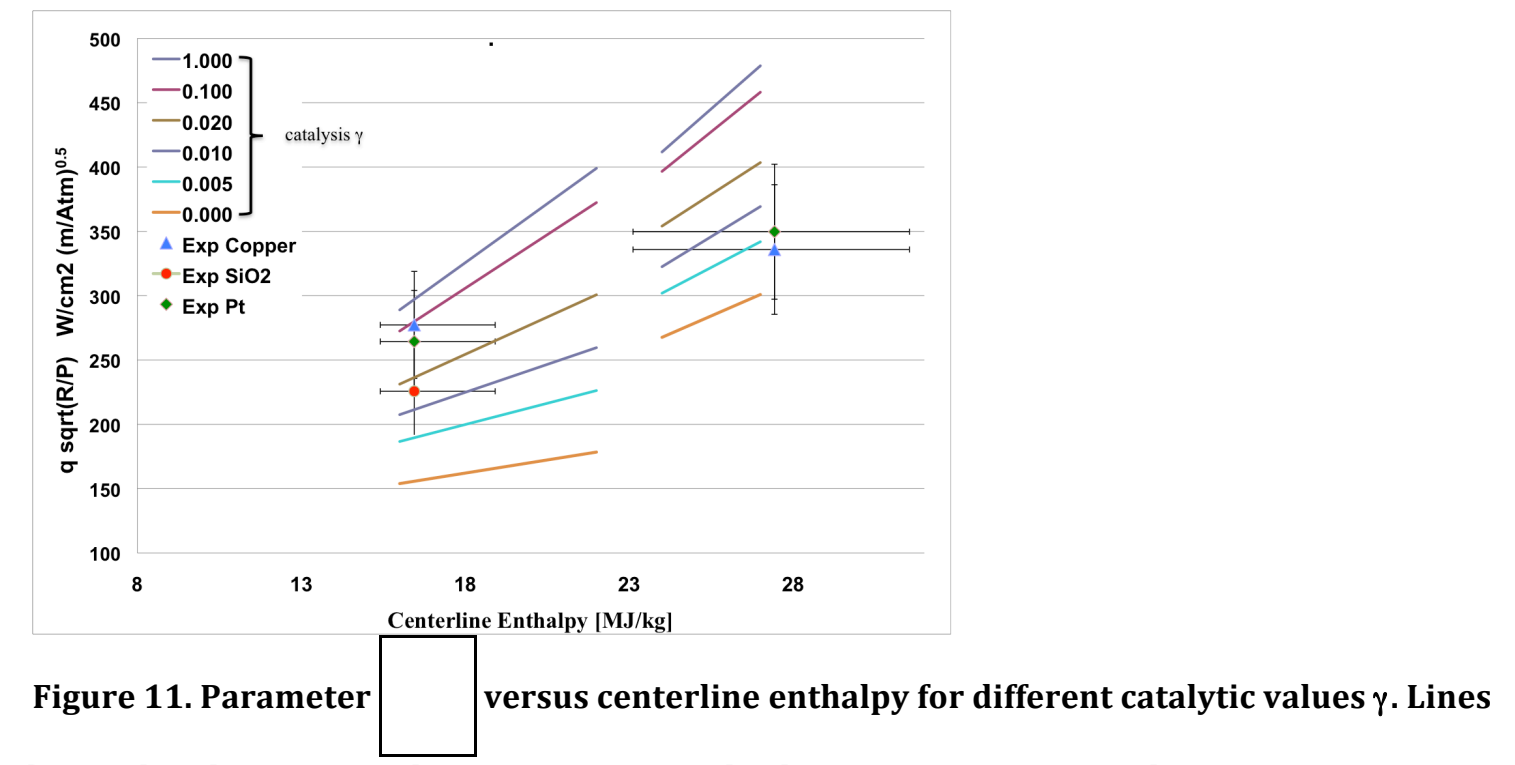

obtained with DPLR simulation, experimental values from AHF copper slug.

\section{Conclusions and Outlook}

Copper surfaces analyzed prior to plasma exposure were found to be cuprous oxide, $\mathrm{Cu}_{2} \mathrm{O}$. All copper slugs inserted into the plasma were found to have oxidized to cupric oxide $\mathrm{CuO}$. This was consistently the case, at low and high enthalpy and with insertion times as short as 0.3 seconds.

When testing other materials like platinum, nickel, constantan, gold and silicon dioxide, cupric oxide was found on all surfaces after plasma exposure in the arc jets.

In future studies, the link between model and experiment through centerline enthalpy needs to be carefully assessed. The linkage is expected to differ between the AHF and IHF arc jet facility because of their intrinsic enthalpy profiles. Repeating previous internal tests with various surface materials at very low pressures, and possibly bypassing copper oxide deposition on the slug surface by shielding it with a Teflon sheet until reaching centerline are next steps towards obtaining measurements with less copper oxide deposit on the surface.

The findings obtained herein make cupric oxide an ideal candidate as surface material for heat flux measurements in arc jets. The use of cupric oxide will allow a constant surface chemistry during the arc jet experiment. In order to assess the stagnation point plasma enthalpy based on the ASTM standard ${ }^{x}$ from heat flux measurements with $\mathrm{CuO}$ properly, its catalytic efficiency needs to be determined in air as a function of temperature. Side arm reactor studies towards this goal are currently ongoing at NASA ARC.

By implementing cupric oxide as surface material for heat flux measurements in arc jets it is expected that the consistency and accuracy of heat flux measurements can be improved. This influence strongly depends on the enthalpy and stagnation pressure at the probe, as well as on the test gas. The model used by Goulard assuming equilibrium free-stream estimates the heat flux of a cupric oxide slug to be 
up to $40 \%$ lower than that measured with a fully catalytic material, depending on enthalpy, stagnation pressure and nose radius. .ii,xvi $^{-}$

\section{Acknowledgements}

We thank the arc-jet crew for their dedication and professionalism carrying out these tests. The support from George Raiche, and discussions with Dinesh Prabhu and Tahir Gökçen are gratefully acknowledged. Exposure to Microwave plasma was possible through hands-on support from Steve Sepka. This work was funded under the NASA Strategic Capabilities Assets Program (SCAP).

\section{References}

i ASTM E457 - 08 Standard Test Method for Measuring Heat-Transfer Rate Using a Thermal Capacitance (Slug) Calorimeter, 2008

ii TSF Branch Level Work Instruction: Surface Preparation of Copper Slug Type and Copper Constantan Calorimeters in Arc-Heated Test Streams, TSF-06-006 iii Goulard, On Catalytic Recombination Rates in Hypersonic Stagnation Heat Transfer, Jet Propulsion, Vol. 28, No. 11, Nov. 1958, pp. 733-745.

iv Cauquot, P. Cavadias, S., Amouroux, J., Thermal Energy Accomodation from Oxygen Atoms Recombination on Metallic Surfaces, Journal of Thermophysics and Heat Transfer, Vol.12, No.2, April- June 1998

v Nawaz, Santos, Assessing Calorimeter Evaluation Methods in Convective and Radiative Heat Flux Environment, AIAA-2010-4905, 10 ${ }^{\text {th }}$ AIAA ASME Joint Thermophysics and Heat Transfer Conference, 2010 vi Hiester, N.K. and Clark, C.F., "Feasibility of Standard Evaluation Procedures for Ablating Materials,” NASA CR-379, Feb. 1966

vii Santos, J., Nawaz, A., Martinez, E., Terrazas-Salinas, I., Volumetric Heat Flux Characterization Experiments in the Interaction Heating Facility at NASA Ames, AIAA 2010-4785, 10th AIAA/ASME Joint Thermophysics and Heat Transfer Conference, 2010

viii ASTM E637-05, Standard Test Method for Calculation of Stagnation Enthalpy from Heat Transfer Theory and Experimental Measurements of Stagnation-Point Heat Transfer and Pressure, 2005 ix Thompson, Prabhu, Terrazas-Salinas, Mach, Bulk Enthalpy Calculation in the Arc Jet Facility at NASA ARC, AIAA2011-3475, 42 nd AIAA Thermophysics Conference, 2011.

x Fay, Riddell, Theory of Stagnation Point Heat Transfer in Dissociated Air, Journal of the Aeronautical Sciences, Vol. 25, No.2, 1958, pp. 73-85.

xi Winovich, On the equilibrium Sonic Method for Evaluating Electric Arc Heater Performance, NASA TN D-2132, 1964

xii Wright, Candler, Bose, Data-Parallel Line Relaxation Method of the Navier-Stokes Equations, AIAA Journal, Vol. 36, No. 9, 1998, pp., 1603-1609.

xiii Pilling, Bedworth, The Oxidation of Metals at High Temperature, from "The Oxidation of Metals" presented at the Annual General Meeting, London, March 1923, pp. $529-581$ 
xiv Marshall, Copeland, Hwang, Wright, Surface Catalysis Experiments on Metal Surfaces in Oxygen and Carbon Monoxide Mixtures, AIAA2006-181, 44 ${ }^{\text {th }}$ AIAA ASME, Jan 9-12, 2006

xv Anderson, Effect of Surface Catalytic Activity on Stagnation Point Heat Transfer Rates, AIAA Journal, V.11, 1973, pp 649-656

xvi Pope, Stagnation Point Convective Heat Transfer in Frozen Boundary Layers, AIAA Journal, Vol. 6, No. 4, 1968, pp. 619-624 